\title{
Flame Retardancy and Thermal Behavior of an Unsaturated Polyester Modified with Kaolinite-Urea Intercalation Complexes
}

\author{
Lina Yue ${ }^{1,+}{ }^{\dagger}$ Junfei Li ${ }^{2,+}$, Xuan Zhou ${ }^{1, *(1)}$, Yingjuan Sun ${ }^{1}$, Ming Gao ${ }^{1}$, Taohua Zhu ${ }^{3}$, \\ Xiaoqian Zhang ${ }^{1}$, Teng Feng ${ }^{1}$, Zhanhong Shi ${ }^{1}$ and Yongchun Liu ${ }^{1}$ \\ 1 Heibei Key Laboratory of Hazardous Chemicals Safety and Control Technology, School of Chemical and \\ Environmental Engineering, North China Institute of Science and Technology, Yanjiao, Beijing 101601, China; \\ yuelina@ncist.edu.cn (L.Y.); syj040520@ncist.edu.cn (Y.S.); gaoming@ncist.edu.cn (M.G.); \\ zhangxiaoqian@ncist.edu.cn (X.Z.); fteng0013@163.com (T.F.); shizhanhong2020@163.com (Z.S.); \\ 17333653645@163.com (Y.L.) \\ 2 School of Materials Science and Engineering, University of Science and Technology Beijing, \\ Beijing 100083, China; junfeili0304@163.com \\ 3 School of Electronic Science and Control Engineering, Institute of Disaster Prevention, \\ Yanjiao, Beijing 101601, China; zhutaohua0812@163.com \\ * Correspondence: 201701255@ncist.edu.cn; Tel.: +86-15624957149 \\ + These authors contributed equally to this work.
}

Received: 26 September 2020; Accepted: 14 October 2020; Published: 15 October 2020 updates

\begin{abstract}
Organic modified kaolinite-urea intercalation complex (KUIC) was prepared using dimethyl sulfoxide (DMSO) as the precursor of kaolinite intercalation. Its structure was characterized by Fourier transform infrared (FTIR) and X-ray diffraction (XRD). Subsequently, as a synergistic agent, KUIC was combined with flame retardant ammonium polyphosphate (APP) to improve the flame retardant and smoke suppression performance of unsaturated polyester (UP) resin. A cone calorimeter (CONE) was used to study its flame retardancy and smoke suppression, and a scanning electron microscope (SEM) and thermogravimetry (TG) were used to study the micro morphology of the char and flame retardant mechanism. The results show that $12 \mathrm{phr}$ of APP and $3 \mathrm{phr}$ of KUIC were doped into UP to obtain a $28.0 \%$ limiting oxygen index (LOI) value. Compared with UP, the heat release rate and smoke production of UP/APP/KUIC composites were greatly decreased. Meanwhile, KUIC indeed enhanced the mechanical properties of UP.
\end{abstract}

Keywords: unsaturated polyester; kaolinite-urea intercalation complex; flame retardant; thermogravimetry

\section{Introduction}

Unsaturated polyester (UP) resins are one of the most widely used types of composite resins, accounting for about $80 \%$ of all thermosetting resins. They have a good range of mechanical properties, corrosion resistance, low weight, and processibility [1-3], and are widely used as matrixes of composite materials for the transportation sector, building industry, and electrical industry, etc. [4]. However, because typical polyester resins are highly flammable and produce large amounts of smoke and toxic acids when burned, their industrial use is limited $[5,6]$.

Therefore, in order to increase and develop their commercial application, the main need is to produce a fire retardant system, reduce fire hazard, and realize fire prevention [7]. Many flame retardants for UP have been found in the past few decades, such as halogenated additives, ammonium salts, zinc compounds, montmorillonite, alumina trihydrate (ATH), zinc stannates, and zinc borate/boric 
acid [8-14]. Although halogenated flame retardants have a good flame retardancy effect, they gradually withdraw from the flame retardancy stage because of their toxic gas production [15]. As a typical halogen-free flame retardant, ammonium polyphosphate (APP) has the best flame retardant effect [1618]. In addition, compared to other halogen-free systems, APP requires lower loadings, ensuring a lower cost, better property retention, and excellent flow [19]. However, the poor compatibility between APP and polymer often leads to the decreased mechanical properties of the materials. In order to improve the above problems, a lot of researchers mainly focus on the following two aspects: the surface modification (or microencapsulation) of existing APP products and the development of an efficient synergistic agent.

Ammonium polyphosphate (APP) is a flame retardant based on phosphorous and ammonium salts. It is a halogen-free flame retardant which is modified and improved with time to comply with environmental issues and evolving regulations [16-18]. The ability of APP to suppress the generation of smoke is attributed to its unique mechanism of intumescence. However, the mechanical properties of most substrates are not good when ammonium polyphosphate is used alone, so it is often compounded with other components to reduce its influence on their mechanical properties.

Kaolinite is one of the most widely distributed clay minerals in nature. In recent years, kaolinite has been widely used in flame retardants and other fields due to its high refractoriness, good thermal insulation and a good chemical stability [20-23]. Kaolin is an inorganic silicon-containing flame retardant with a low cost and significant smoke suppression effect. When the polymer is burned, silica is formed to cover the char layer, which plays a double role of adiabatic and shielding. However, untreated kaolinite tends to aggregate in the polymer and is required to be flame retardant in large amounts [24]. Kaolinite can be inserted in dimethyl sulfoxide (DMSO), urea, amino silane, and other high-polarity molecules, resulting in an increase in the base spacing [25-27]. Meanwhile, nitrogen, silicon, sulfur, and other elements in these compounds have flame retardant effects, which can theoretically improve the flame retardant effects of kaolinite.

In this study, using DMSO as the precursor of kaolinite intercalation, we prepared kaolinite-urea intercalation complexes (KUIC) by replacing the DMSO with urea. Then, KUIC, acting as a synergistic agent, was combined with APP in the UP system to study its influence on the thermal stability of UPR and the effect of the flame retardant and smoke suppression. Its thermal behavior and burning behavior were characterized by TG, limiting oxygen index (LOI), cone calorimeter (CONE), and SEM.

\section{Results and Discussion}

\subsection{Characterization of Kaolinite and KUIC}

The FTIR spectrum of parent clay kaolinite is shown in Figure 1a and Table 1. The absorptions at $3416 \mathrm{~cm}^{-1}$ in the $-\mathrm{OH}$ stretching region were attributed to the inner-surface -OH group [28]. Meanwhile, the major bands in the FTIR spectrum characterizing the KUIC molecule at 3460 and $3358 \mathrm{~cm}^{-1}$ in the $-\mathrm{NH}$ stretching region were attributed to the asymmetric and symmetric stretching vibrations of $\mathrm{NH}_{2}$ groups, which are hydrogen-bonded [29]. In addition, in the 1690-1400 $\mathrm{cm}^{-1}$ spectral range, three absorptions at 1673,1631 , and $1452 \mathrm{~cm}^{-1}$ can be observed. The vibration with the highest frequency is identified as the $-\mathrm{C}=\mathrm{O}$ stretching vibration of urea. The next two bands belong to the deformation vibration of $-\mathrm{N}-\mathrm{H}$ and the stretching vibration of $-\mathrm{C}-\mathrm{N}$. Si-O deformation bands are located in the $1200-1000 \mathrm{~cm}^{-1}$ region. In addition, the SEM-EDS spectrum also indicated that $\mathrm{C}$ and $\mathrm{N}$ elements were detected on the KUIC surface (see Figure 1c,d).

When organic molecules are inserted into the interlayers of kaolinite, the interlayer spacing of kaolinite will be more or less affected. By comparing the interlayer spacing of kaolinite before and after the insertion of small organic molecules, we can know whether organic molecules are inserted into the interlayers of kaolinite. From Figure 1b, the interlayer spacing of kaolinite original soil is $0.69 \mathrm{~nm}$. When organic molecules are inserted into the interlayer of kaolinite, interlayer expansion is caused, and the interlayer spacing increases correspondingly. According to the FTIR and XRD results, 
DMSO was successfully substituted into the interlayer of kaolinite by urea, and the interlayer spacing of kaolinite was increased from 0.69 to $0.78 \mathrm{~nm}$.
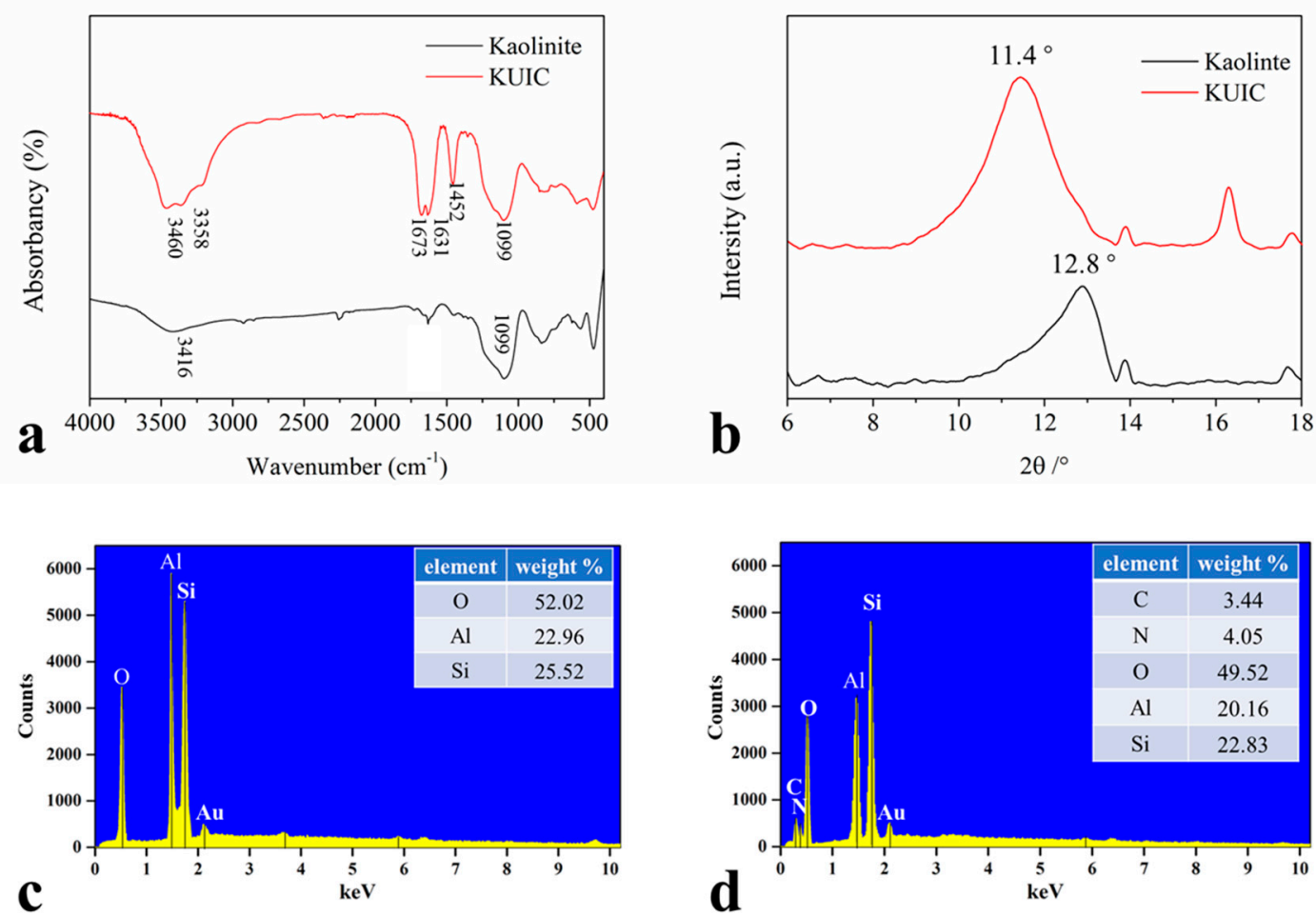

Figure 1. FTIR spectra (a) and XRD curves (b) of kaolinite and KUIC, and the elemental analyses of kaolinite (c) and KUIC (d).

Table 1. Characteristic bands of kaolinite and KUIC.

\begin{tabular}{|c|c|c|}
\hline Kaolinite $/ \mathrm{cm}^{-1}$ & $\mathrm{KUIC} / \mathrm{cm}^{-1}$ & FTIR of Vibration Properties \\
\hline- & 3460 & symmetric stretching modes of $-\mathrm{N}-\mathrm{H}$ \\
\hline 3416 & & stretching mode of $-\mathrm{O}-\mathrm{H}$ \\
\hline \multirow[t]{2}{*}{-} & 3358 & asymmetric stretching modes of $-\mathrm{N}-\mathrm{H}$ \\
\hline & 1673 & stretching mode of $-\mathrm{C}=\mathrm{O}$ \\
\hline- & 1631 & deformation vibration of $-\mathrm{N}-\mathrm{H}$ \\
\hline- & 1452 & stretching vibration of -C-N \\
\hline 1099 & 1099 & deformation vibration of $-\mathrm{Si}-\mathrm{O}$ \\
\hline
\end{tabular}

\subsection{Flame Retardancy}

Limiting oxygen index (LOI) is a fundamental tool in basic research on polymer combustion and the mechanism of flame retardancy. LOI also provides an evaluation of the intrinsic flammability of polymeric materials [30]. The flammability of UP samples is evaluated by determining their limiting oxygen indexes, and these values are presented in Table 2. The LOI value of neat UP is $21.0 \%$, which increases from $24.8 \%$ to $28.7 \%$ as the APP content is increased from 10 to $25 \mathrm{phr}$, respectively, which shows the very good flame retardancy of APP. The LOI value of UP containing different amounts of APP is increased due to the presence of phosphorus and nitrogen in APP. Phosphorus and nitrogen have a synergistic effect between them, which enhances the LOI of UP. The trend of these data shows that the LOI increases with the increasing content of APP. Meanwhile, there is a similar trend of LOI values from $26.5 \%$ to $28.3 \%$, with the increasing content of KUIC from 1.0 to $4.0 \mathrm{phr}$, though the increases are much little, which is due to the limited flame retardancy of KUIC, but this is better than that of kaolinite because of the higher LOI for UP-9 of $28.3 \%$ than for UP- 6 of $27.3 \%$. The results of the UL 94 test showed that the combustion rating of the composites containing 
flame retardant and clay (kaolinite or KUIC) reached a V0 rating and V1 rating. When 15\% APP was added, the UP composites reached a V0 rating, and the addition of clay (kaolinite and KUIC) had no effect on the combustion rating of the UP composites; all reached the V0 rating (shown in Figure 2).

Table 2. Data of the LOI, EFF, and SE of UP and its composites.

\begin{tabular}{|c|c|c|c|c|c|c|c|}
\hline Sample & $\omega_{(\mathrm{APP})} / \%$ & $\omega_{\text {(Kaolinite) }} / \%$ & $\omega_{(\text {KUIC) }} / \%$ & LOI/\% & $\Delta_{(\mathrm{LOI})} / \%$ & EFF & SE \\
\hline UP-1 & - & - & - & 21.0 & - & - & - \\
\hline UP-3 & 15 & - & - & 26.2 & 5.2 & 0.35 & - \\
\hline UP-6 & 12 & 3 & - & 27.3 & 6.3 & 0.42 & 1.20 \\
\hline UP-7 & 14 & - & 1 & 26.5 & 5.5 & 0.37 & 1.06 \\
\hline UP-8 & 13 & - & 2 & 27.1 & 6.1 & 0.41 & 1.17 \\
\hline UP-9 & 12 & - & 3 & 28.0 & 7.0 & 0.47 & 1.34 \\
\hline UP-10 & 11 & - & 4 & 28.3 & 7.3 & 0.49 & 1.40 \\
\hline
\end{tabular}

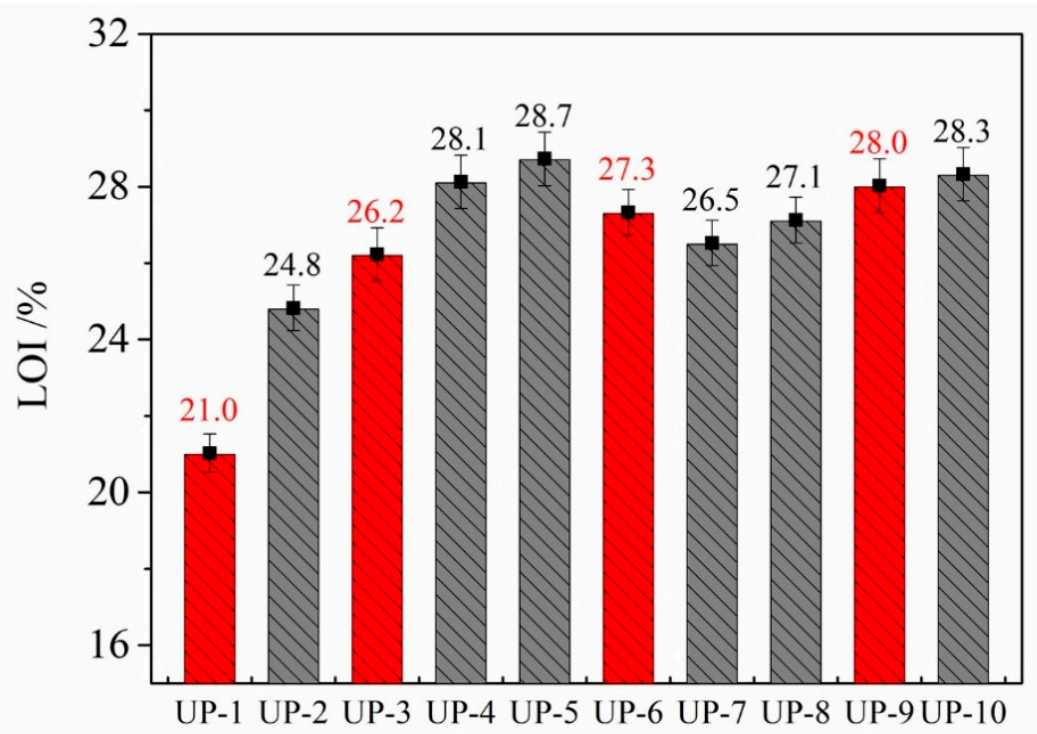

Figure 2. LOI values of all the UP samples.

The synergistic effectivity (SE) and flame retardant effectivity (EFF) are often used to evaluate the synergistic flame retardant effect of a system. EFF is defined as the increase rate of the oxygen index for every $1 \%$ increase in the flame retardant effects; SE is defined as the ratio of the flame retardancy with and without synergistic agents. The corresponding calculation formulas are as follows:

$$
\begin{gathered}
\mathrm{EFF}=\frac{\Delta(\mathrm{LOI})}{\omega(\mathrm{APP})+\omega(\text { Kaolinite or KUIC })} \\
\mathrm{SE}=\frac{E F F *}{E F F 0}
\end{gathered}
$$

where "*" is the sample for UP/APP/kaolinite or UP/APP/KUIC, and " 0 " is the sample for the UP/APP. When SE > 1, APP and clay (kaolinite or KUIC) have a synergistic effect on the flame retardancy; the greater the SE value, the better the synergistic flame retardant efficiency. The calculation results of EFF and SE are summarized in Table 2. It can be seen that, with the gradual addition of KUIC, the EFF value and SE value show a trend of increase, and the synergistic efficiency of APP and KUIC is greater than 1, which shows that APP and KUIC have synergistic flame retardant effects. 


\subsection{Mechanical Properties}

The mechanical properties of UP are important parameters that determine its applications, such as in load bearing and as packaging materials. Tensile strength and impact strength are very important parameters corresponding to mechanical properties. To study the effect of the APP and KUIC loading on the mechanical properties of UP, the tensile strength and impact strength of UP containing different APP and KUIC loadings were determined and are shown in Figure 3. These indicate that the tensile strength and impact strength of UP decreased with increases in the APP loading. This decrease in the mechanical properties was due to its poor wetting or adhesion with the polymer matrix; this also, with the inclusion of higher amounts, leads to agglomeration, because the filler-filler interaction becomes more pronounced. However, the decreases in the mechanical properties are less than $20 \%$ with lower loadings of APP (below 15 phr) - only 19\% for the tensile strength and 15\% for the impact strength for UP-3 containing 15 phr of APP, which has good flame retardancy with a LOI of 26.2\%.
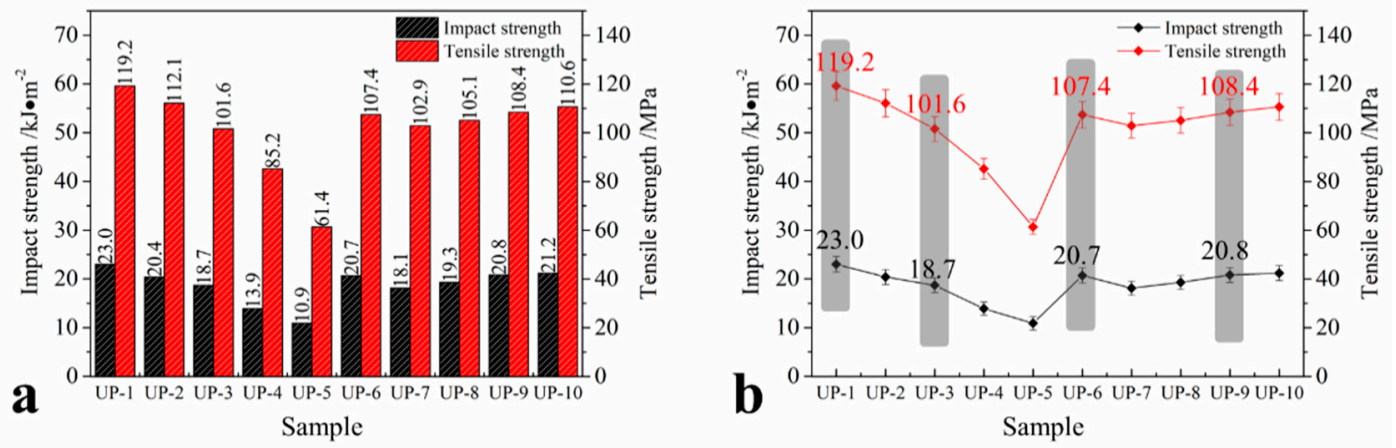

Figure 3. Impact strength (a) and tensile strength (b) of the UP samples.

On the other hand, from Figure 3 the tensile strength and impact strength increased with increases in the KUIC loading, and there is no obvious difference between kaolinite and KUIC. The enhancements are mainly attributed to the goof dispersion and high exfoliation of the silicate layers in the UP matrix, which provided high resistance against the plastic deformation and the effect of the stretching of the oriented backbone bonds of the polymer chains in the gallery [31].

\subsection{Cone Calorimeter Test}

The cone calorimeter was an ideal instrument to evaluate realistically the combined flame-retarding and smoke-suppressing behavior of polymer. Some cone calorimeter results have been found to correlate well with those obtained from large-scale fire tests and can be used to predict the behavior of materials in real fires. Some of the important parameters of PU-1, PU-3, PU-6, and PU-9 derived from the cone calorimeter are shown in Figure 4 and Table 3.

Figure 4a shows the heat release rate (HRR) curves as functions of the combustion time of all the samples. The HRR and peak HRR decreased markedly when UP is composited with APP, kaolinite, and KUIC. From Figure 4a and Table 3, it can be seen that the peak HRR of UP-3 is $240.7 \mathrm{~kW} \cdot \mathrm{m}^{-2}$, which decreased by $33.4 \%$ compared with UP-1 $\left(361.2 \mathrm{~kW} \cdot \mathrm{m}^{-2}\right)$. This is because APP can promote charring to form carbonaceous materials, which can insulate oxygen and heat during combustion. For UP-6, the peak HRR is $225.9 \mathrm{~kW} \cdot \mathrm{m}^{-2}$, lower than that of UP-3, which may be due to the fact that kaolinite improves the thermal stabilities of UP, as mentioned above. The peak HRR is $205.4 \mathrm{~kW} \cdot \mathrm{m}^{-2}$ for UP-9, which decreased by $43 \%$ compared with UP-1. This is lowest peak HRR in all the samples, which may be due to the fact that the KUIC can greatly increase the thermal stabilities of UP or probably promote the UP product with much more compact and continuous char yields because of the synergistic effect between APP and KUIC. Meanwhile, at $1200 \mathrm{~s}$ the total heat release (THR) of the UP-3, UP-6, and UP-9 samples was lower than that of the UP-1 sample. As a result, the THR of UP-9 
declined from $103751 \mathrm{MJ}$ of pure UPR to $66114 \mathrm{MJ}$ and reduced by $36.3 \%$. It was concluded that the addition of APP and KUIC effectively constrained the heat release of the UP thermosets.
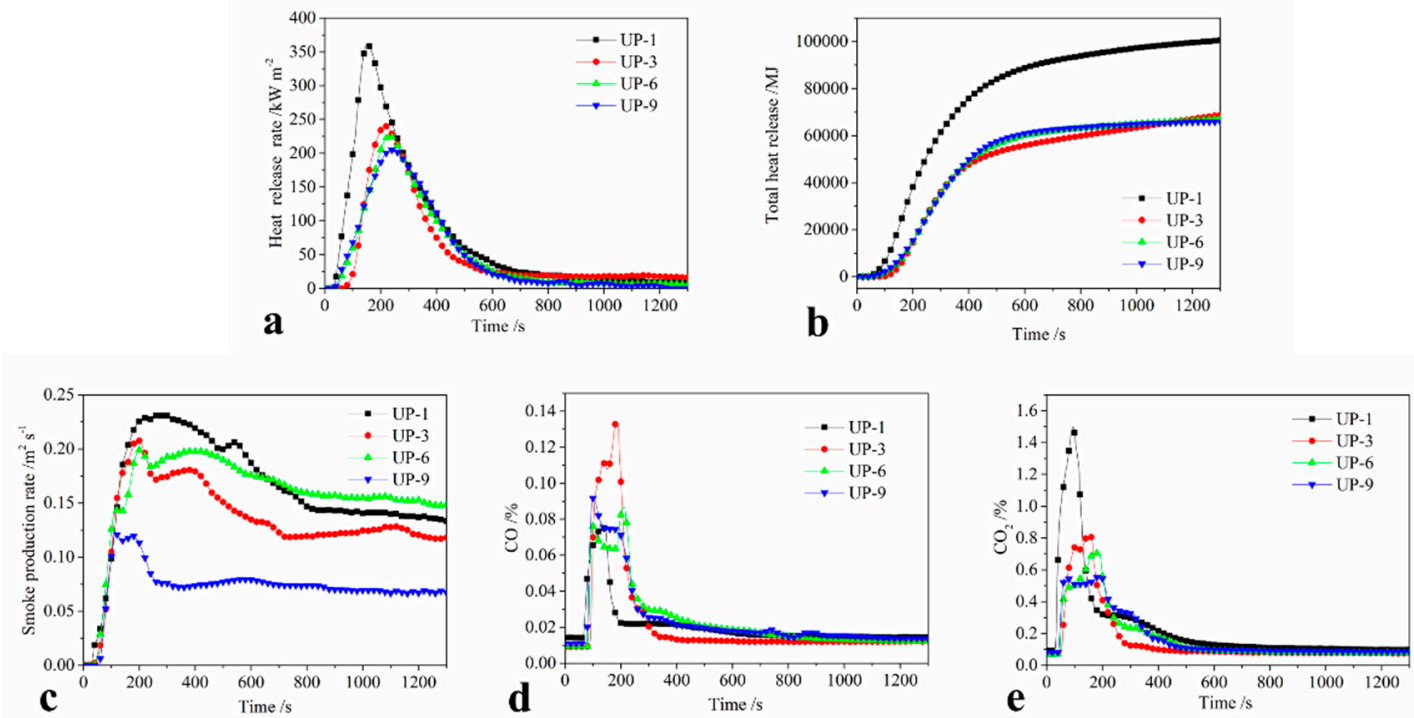

Figure 4. The cone calorimeter test curves of UP samples: (a) heat release rate, (b) total release rate, (c) smoke production rate, (d) $\mathrm{CO}$ yield, and (e) $\mathrm{CO}_{2}$ yield.

Table 3. The cone calorimeter test data of the UP samples.

\begin{tabular}{ccccc}
\hline & UP-1 & UP-3 & UP-6 & UP-9 \\
\hline peak HRR $/ \mathrm{kW} \cdot \mathrm{m}^{-2}$ & $361.2 \pm 1.6$ & $240.7 \pm 3.7$ & $225.9 \pm 2.5$ & $205.4 \pm 1.9$ \\
$\mathrm{THR} / \mathrm{MJ}$ & $103751 \pm 45$ & $69125 \pm 23$ & $67178 \pm 51$ & $66114 \pm 37$ \\
peak SPR $/ \mathrm{m}^{2} \cdot \mathrm{s}^{-1}$ & $0.23 \pm 0.06$ & $0.21 \pm 0.04$ & $0.20 \pm 0.05$ & $0.12 \pm 0.03$ \\
$\mathrm{TSP} / \mathrm{m}^{2} \cdot \mathrm{kg}^{-1}$ & $197.5 \pm 4.1$ & $190.2 \pm 3.4$ & $161.2 \pm 1.7$ & $121.7 \pm 2.1$ \\
$\mathrm{CO}$ yield $/ \%$ & $0.07 \pm 0.01$ & $0.13 \pm 0.03$ & $0.08 \pm 0.02$ & $0.09 \pm 0.03$ \\
$\mathrm{CO}_{2}$ yield $/ \%$ & $1.50 \pm 0.21$ & $0.81 \pm 015$ & $0.71 \pm 0.11$ & $0.55 \pm 0.10$ \\
\hline
\end{tabular}

Generally, the $\mathrm{CO}_{2}$ release from materials is closely related to their inflammability; the more $\mathrm{CO}_{2}$ there is, the more the inflammability there is. Meanwhile, the $\mathrm{CO}$ productions are due to the incomplete combustion of the materials. Figure $4 \mathrm{~d}$,e show the $\mathrm{CO}_{2}$ and $\mathrm{CO}$ content in the gas products from the samples, respectively, and the corresponding data are shown in Table 3. The $\mathrm{CO}_{2}$ release of pure UP is more and faster than that of other samples, which indicates that UP sharply burns and completes in 600 s. The $\mathrm{CO}_{2}$ content is significantly decreased for other samples in the burning products. The $\mathrm{CO}_{2}$ content of PU-3, PU-6, and PU-9 is $0.81 \%, 0.71 \%$, and $0.55 \%$, respectively, which indicates their different flame retardancy, which is better for PU-3 and PU-6 and best for PU-9, and is in agreement with the results of HRR and LOI. A similar rule is shown for the CO release as in Figure $4 \mathrm{~d}$. From Figure $4 \mathrm{e}$, we can see that the CO release of the flame retardant UP (PU-3, PU-6, PU-9) is more than that of the pure UP sample, since it means the incomplete combustion of the materials. Moreover, the CO content of PU-9 is less than that of PU-3 and PU-6, which is very favorable for its practical application with the best flame retardancy and the lowest toxicity.

Meanwhile, the smoke production along with the heat release rate plays a critical role in fire conditions. Figure $4 \mathrm{c}$ and Table 3 show that the peak smoke production rate (SPR) of samples decreased to different degrees after adding the flame retardant. The total smoke production (TSP) of UP-6 decreased from $190.2 \mathrm{~m}^{2} \cdot \mathrm{kg}^{-1}$ (UP-3) to $161.2 \mathrm{~m}^{2} \cdot \mathrm{kg}^{-1}$ after the addition of kaolinite, which shows that kaolin can increase the stability of the carbon layer and inhibit the emission of smoke. With the presence of $15 \mathrm{phr}$ APP and 3 phr KUIC, the smoke suppression of the UP-9 sample is more prominent, and the TSP of UP-9 $\left(121.7 \mathrm{~m}^{2} \cdot \mathrm{kg}^{-1}\right)$ decreases by $38.4 \%$ compared with that of pure UP $\left(197.5 \mathrm{~m}^{2} \cdot \mathrm{kg}^{-1}\right)$. 
KUIC can promote the thermal decomposition of UPR to form a denser carbon layer and inhibit the combustion of UPR, thus slowing down the heat release rate of UPR and reducing the total amount of smoke.

\subsection{Thermal Degradation}

When flame retardants are incorporated into polymeric materials, the weight loss pattern of polymers is altered. Phosphorus-nitrogen groups decompose at relatively lower temperatures to form a heat-resistant char, retarding the weight loss rate of the polymers at higher temperatures through condensed-phase mechanisms [32].

The measurement of the TG and DTG curves of UP-1, UP-3, UP-6, and UP-9 was carried out in dynamic air from an ambient temperature to $800^{\circ} \mathrm{C}$, and they are shown in Figure 5. The initial decomposition temperature (IDT) was determined by a $5 \%$ weight loss, showing the samples beginning to degrade, and indicates the apparent thermal stability of the samples. The integral procedure decomposition temperature (IPDT) was determined by a $50 \%$ weight loss, and exhibits the samples' inherent thermal stability. The weight loss (WL) at main decomposition, the char yield (CY) at $700^{\circ} \mathrm{C}$, the temperatures at the maximum weight loss rate $\left(T_{\max }\right)$, and the value of the maximum weight loss rate $\left(R_{\max }\right)$ were measured and are listed in Table 4.
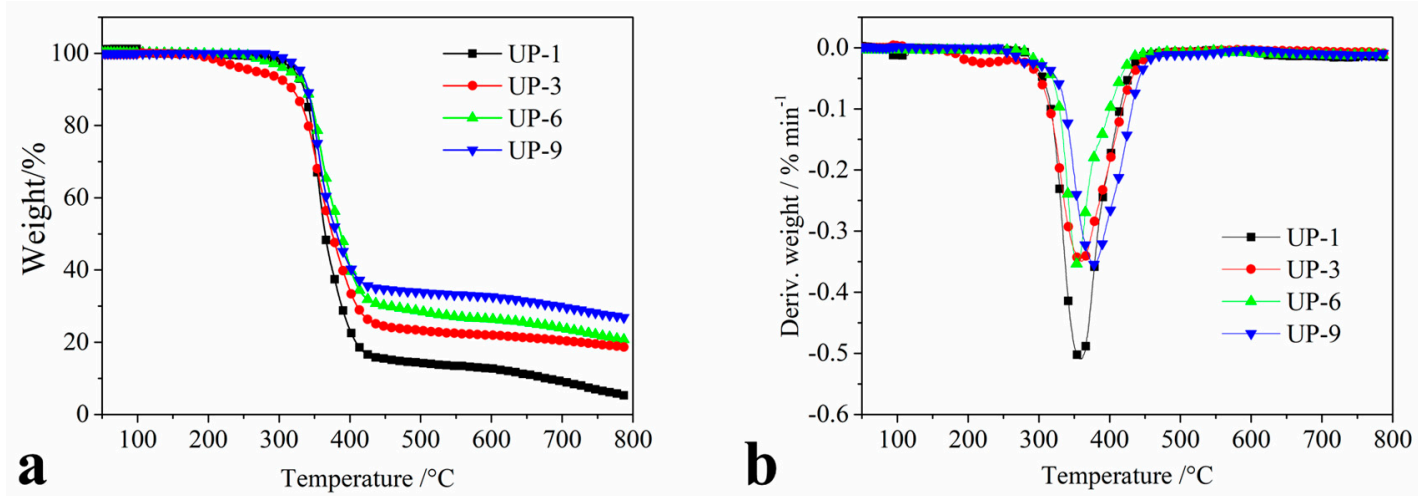

Figure 5. (a) TGA and (b) DTG curves of the UP samples under nitrogen.

Table 4. Thermal data of the UP samples from the thermogravimetric analysis.

\begin{tabular}{ccccccc}
\hline No. & $\begin{array}{c}\text { IDT } \\
{ }^{\circ} \mathbf{C}\end{array}$ & $\begin{array}{c}\text { IPDT } \\
{ }^{\circ} \mathbf{C}\end{array}$ & $\begin{array}{c}\text { WL } \\
\boldsymbol{~} \%\end{array}$ & $\begin{array}{c}\mathbf{C Y} \\
\boldsymbol{~} \%\end{array}$ & $\begin{array}{c}\boldsymbol{T}_{\max } \\
{ }^{\circ} \mathbf{C}\end{array}$ & $\begin{array}{c}\boldsymbol{R}_{\max } \\
\% / \text { min }\end{array}$ \\
\hline UP-1 & 321 & 364 & 78.0 & 9.1 & 359 & 0.51 \\
UP-3 & 252 & 375 & 69.1 & 20.6 & 359 & 0.35 \\
UP-6 & 305 & 380 & 65.6 & 22.1 & 351 & 0.33 \\
UP-9 & 310 & 386 & 62.8 & 24.5 & 378 & 0.36 \\
\hline
\end{tabular}

The results indicate that neat UP is thermally stable below $300{ }^{\circ} \mathrm{C}$, and IDT is $321^{\circ} \mathrm{C}$. It has a small amount of volatile until the temperature rises to $340{ }^{\circ} \mathrm{C}$, and it has a weight loss of less than $20 \%$ at $340{ }^{\circ} \mathrm{C}$. When the temperature further increases, the weight loss increases rapidly and a quantity of volatile is produced until it almost exhausts at $420{ }^{\circ} \mathrm{C}$, and the char yields at $700{ }^{\circ} \mathrm{C}$ are $9.1 \%$. The TG and DTG curves of UP/APP (UP-3) are different. It is noted that IDT (252 $\left.{ }^{\circ} \mathrm{C}\right)$ and $R_{\max }$ $(0.35 \% / \mathrm{min})$ are decreased while the char yields $(20.6 \%)$ are increased. This is because the APP in UP-3 begins to decompose at relative low temperatures, generating some small molecules such as phosphoric acid, water, ammonia, etc. [33]. With the increase in temperature, it is observed that APP can increase the number of residues remarkably, which means that APP promotes charring to form carbonaceous materials. This is one of the reasons for the improvement in the flame retardancy of UP. $R_{\text {max }}$ is decreased in the UP/APP/kaolinite (UP-6), and its char yields are increased. Its IDT is increased compared with that of UP-3 and UP, which indicates the kaolinite can improve the thermal stabilities 
of UP. UP/APP/KUIC (UP-9) has similar thermal behaviors to those of UP/APP, and $R_{\max }(0.36 \% / \mathrm{min})$ is decreased, while the char yields $(24.5 \%)$ are remarkably increased. Meanwhile, its IDT (310 $\left.{ }^{\circ} \mathrm{C}\right)$ is increased, which shows that the thermal stabilities of UP are improved by the incorporation of KUIC. It is possible that KUIC can form an effective charring layer in lower decomposition, preventing the char layer from oxidation, and getting good flame retardancy due to the synergistic effect between APP and KUIC. The higher LOI values in Table 2 support this notion.

The thermal stability of the UP is assessed by two parameters: IDT and IPDT. IDT indicates the apparent thermal stability of the UP resins-i.e., the failure temperatures of the resins in processing and moulding. On the other hand, IPDT exhibits the inherent thermal stability of the resins, i.e., the decomposition characteristics of the volatile composition. From Table 4, flame retardant UP (UP-3, UP-6, UP-9) show relatively lower IDTs than do the neat resin (UP-1), since APP decomposes at low temperatures. On the other hand, the existence of kaolinite (in UP-6) and KUIC (in UP-9) exhibits higher IPDT than the UP containing only APP (UP-3), exhibiting a higher thermal stability, especially for KUIC.

\subsection{Morphology of Residual Char}

It is well known that an effective protective char layer could improve the flame retardancy of materials during combustion. The TG results indicate that the char yields of UP-3, UP-6, and UP-9 are increased by the incorporation of APP, kaolinite, and KUIC. This is necessary but not sufficient to ensure fire protection, because the char formed may be too light and not sufficiently mechanically resistant. A structure with a relatively strong char layer is important to minimize the heat transfer and provide good protection for the substrate [34]. Thus, the morphologies of the residual char were investigated by SEM. Figure 6 shows the SEM micrographs of the residual char from the combustion of UP-1, UP-3, UP-6, and UP-9 after the CONE test. As can be seen from Figure 6a, it is obvious that loose and flaky char is observed at the outer surface of UP, with many large holes scattered on the surface which could not protect the underlying material from fire. From Figure $6 \mathrm{~b}$, we can see that a continuous char is formed in the interior part, which corresponds to the condensed-phase mechanisms of APP. However, there are a few holes or bubbles on the surface. However, due to the presence of clay, the surface continuity of the condensed char layer of UP-6 is worse than that of UP-3, as shown in Figure 6c. Meanwhile, the char residue of UP-9 depicted in Figure 6d exhibits a much more compact and continuous morphology compared with that of the other UP samples. A honeycomb-like structure is obtained within the residual char, indicating the formation of a strong charred layer during combustion. It has been reported [35] that honeycomb-like char probably exhibits much better heat insulation and mechanical properties. Based on the SEM result, it is reasonable to believe that the formation of a cohesive and dense structure of residual char is responsible for the thermal stability and flammability properties. The formation of efficient char for UP-9 can prevent heat transfer between the flame zone and the substrate, and thus protect the underlying materials from further burning and pyrolysis.

\subsection{Flame Retardant Mechanism}

Combined with the before-mentioned analysis and some previous literature [36-38], a possible flame retardant mechanism of the UP/APP/KUIC composites is proposed in Figure 7 . In the pure sample exposed to a heat source, the resulting carbon layer was unable to isolate oxygen and heat transfer, causing the polymer to burn violently. However, when exposed to a radiation heat source, phosphoric acid and metaphosphoric acid are released by APP, and the obtained acid can catalyze the intramolecular or intermolecular dehydration of UP composites to form cokes. The resulting cross-linked cokes play a very good role in thermal insulation and oxygen shielding. In addition, APP is decomposed into a lot of none-flammable gas products $\left(\mathrm{NH}_{3}, \mathrm{H}_{2} \mathrm{O}\right)$, which reduces the concentration of flammable gases and oxygen in the gas phase, thus preventing further burning of the base material. Meanwhile, a lot of phosphorus free radicals $\left(\mathrm{HPO} \bullet, \mathrm{PO}_{2} \bullet, \mathrm{PO} \bullet\right.$ and $\mathrm{HPO}_{2} \bullet$ ) are produced during 
combustion, which capture $\mathrm{H} \bullet$ and $\mathrm{OH} \bullet$ free radicals [38]. In here, the KUIC nanomaterials further promote the UP/APP system to form a dense coke layer at the interface between the gas phase and the condensed phase, acting as a barrier for heat exchange and mass exchange. The introduction of urea between the kaolin layers not only improved the dispersion of clay, but also showed a good synergistic effect with the APP. The char network formed by KUIC and crosslinked polyphosphoric acid can be strengthened, making the char more stable, and acts as an oxygen-insulating and heat-insulating function, ultimately achieving flame retardancy.
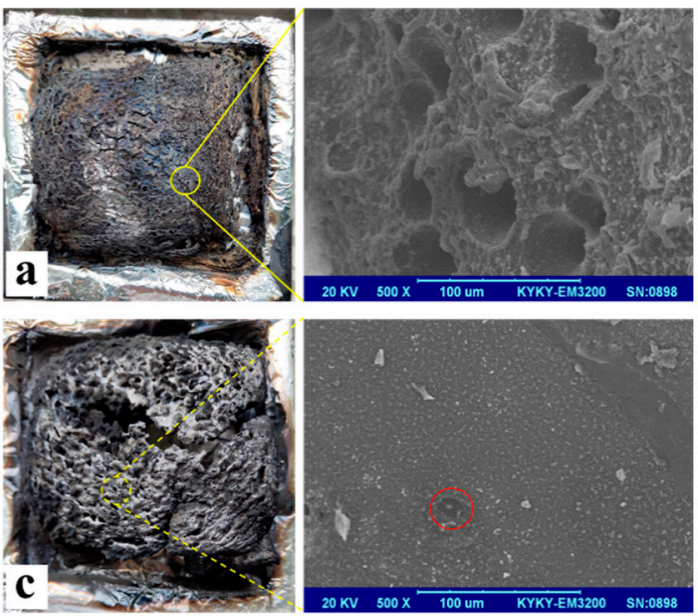
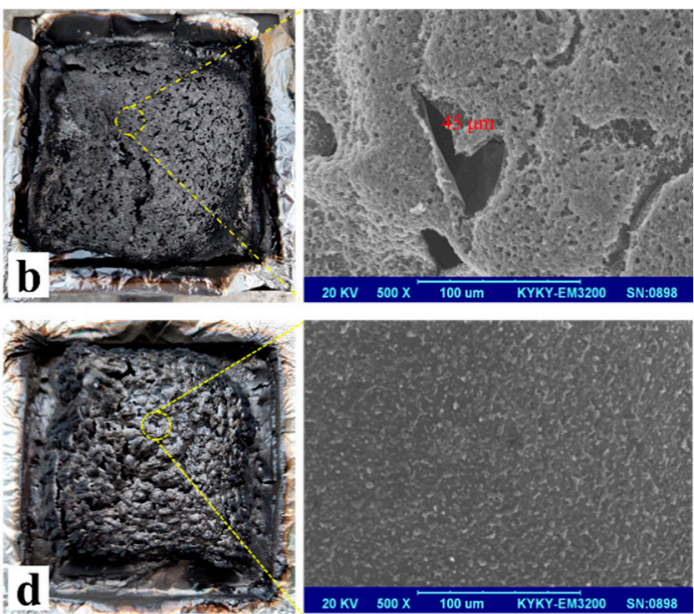

Figure 6. Digital images and SEM micrographs of the residual char from the combustion of UP-1 (a), UP-3 (b), UP-6 (c), and UP-9 (d) after the cone calorimeter test.

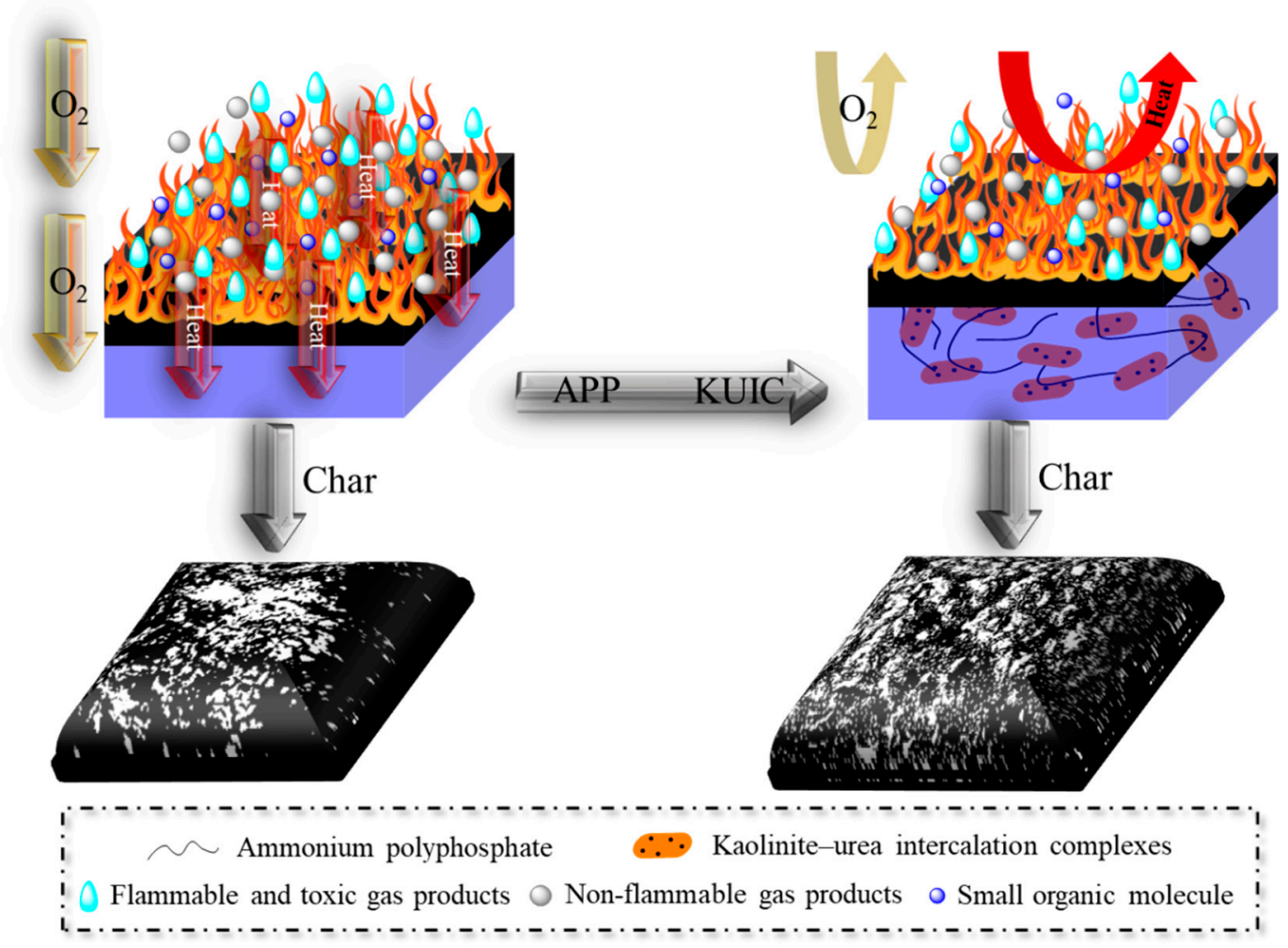

Figure 7. Proposed flame retardant mechanism of the UP/APP/KUIC samples. 


\section{Materials and Methods}

\subsection{Materials}

Orthophthalic unsaturated polyester resin (UP, type:191\#, commercial grade), curing agent methyl ethyl ketone peroxide (MEKP), and accelerant agent cobalt naphthenate were purchased from Central Henan Yizhiyuan chemical products Co., LTD. Dimethyl sulfoxide (DMSO, 99.8\%, AR) and urea (99\%, AR) were supplied by Tianjin Fuchen chemical Reagent Co., Ltd. (Tianjin, China), and kaolinite (98\%, CP) was obtained from Tianjin Zhiyuan chemical reagent Co., Ltd. (Tianjin, China). APP was bought from the Tangshan Yongfa flame retardant material factory (Tangshan, China).

\subsection{Preparation KUIC of UP/APP/KUIC Composites}

KUIC is prepared by intercalating dimethyl sulfoxide with kaolin and then replacing it with urea [39]; a composite schematic diagram of KUIC is shown in Figure 8. The formulation of the composites mainly included polyester, curing agent, accelerator, APP, and KUIC. Composite sample formulations were prepared by adding different amounts of KUIC to UP. The formulation of the composites prepared was specified in the Table 5. The UP, curing agent, and accelerator were initially mixed and then APP and KUIC were added and mixed for about $5 \mathrm{~min}$. Then, the mixture was poured into aluminum molds. The composites were cured for $20 \mathrm{~min}$ at $25^{\circ} \mathrm{C}$ and post cured at $50{ }^{\circ} \mathrm{C}$ for $5 \mathrm{~h}$.
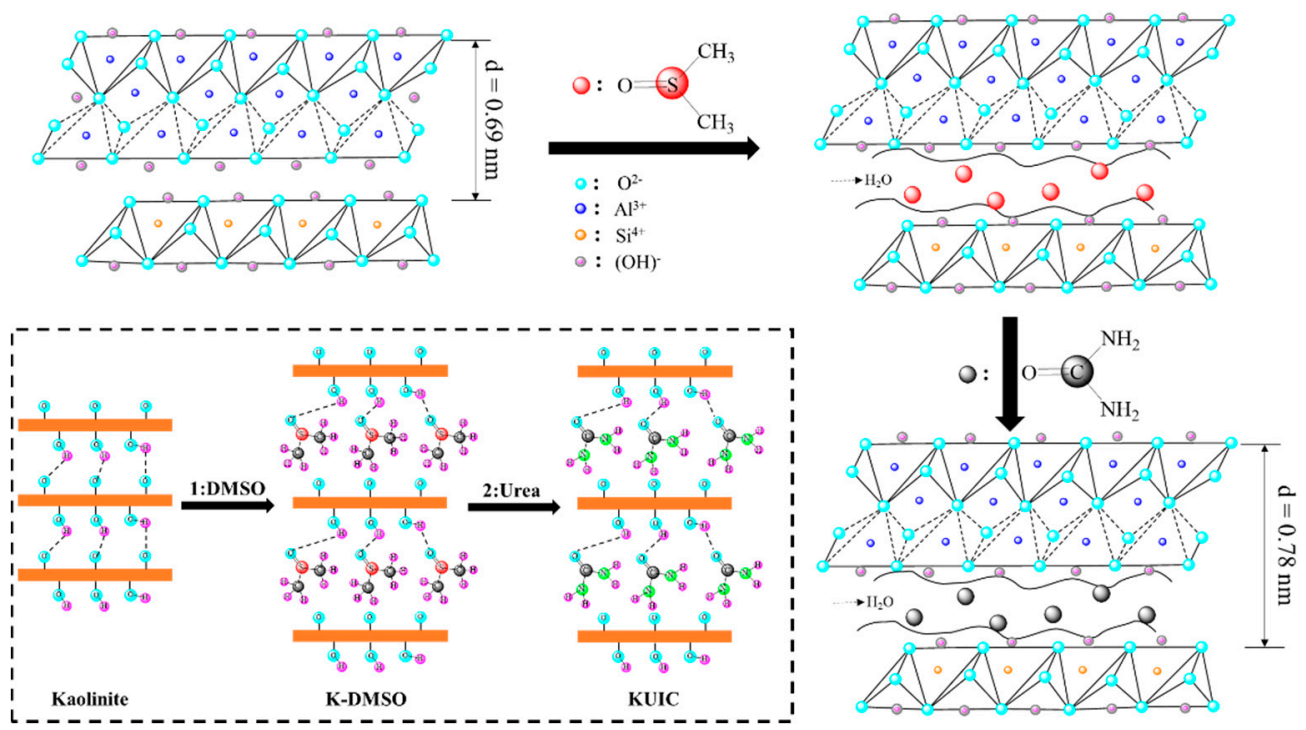

Figure 8. Preparation process of the kaolinite-urea intercalation complex.

Table 5. Composition of the UP samples.

\begin{tabular}{ccccccc}
\hline No. & UP/phr & Curing agent/phr & Accelerator/phr & APP/phr & Kaolinite/phr & KUIC/phr \\
\hline UP-1 & 94 & 3 & 3 & - & - & - \\
UP-2 & 84.6 & 2.7 & 2.7 & 10 & - & - \\
UP-3 & 79.9 & 2.55 & 2.55 & 15 & - & - \\
UP-4 & 75.2 & 2.4 & 2.4 & 20 & - & - \\
UP-5 & 70.5 & 2.25 & 2.25 & 25 & - & - \\
UP-6 & 79.9 & 2.55 & 2.55 & 12 & 3 & - \\
UP-7 & 79.9 & 2.55 & 2.55 & 14 & - & 1 \\
UP-8 & 79.9 & 2.55 & 2.55 & 13 & - & 2 \\
UP-9 & 79.9 & 2.55 & 2.55 & 12 & - & 3 \\
UP-10 & 79.9 & 2.55 & 2.55 & 11 & - & 4 \\
\hline
\end{tabular}




\subsection{Testing}

The characterizations of all samples by X-ray diffraction (XRD) were carried out with an X-ray diffractometer (RAD-3C, Rigaku, Japan). We used $\mathrm{Cu} \mathrm{K} \alpha$ radiation $(\mathrm{K} \alpha=1.54 \AA$ ) operating at $40 \mathrm{kV}$ and $40 \mathrm{~mA}$. The scanning rate was $2^{\circ} / \mathrm{min}$. Fourier transform infrared (FTIR) spectroscopy analyses were performed with an FTS 2000 FTIR (Varian, Ok, USA). We used this spectrometer in the FTIR range of $4000-400 \mathrm{~cm}^{-1}$. The limiting oxygen index (LOI) test was performed with a JF-3 oxygen index test instrument (Jiangning, China) in terms of the standard LOI test, ASTM D 2863-97. The specimen size for the LOI measurement was $130 \times 6.5 \times 3 \mathrm{~mm}^{3}$. The UL 94 rating test used a PX03001-02 vertical combustion tester (PHINIX, jiangsu China) according to GB/T 5169 (sample dimension: $3.2 \mathrm{~mm} \times 12.7 \mathrm{~mm} \times 127 \mathrm{~mm}$ ). Thermogravimetry (TG) was carried out on an HCT-2 thermal analyzer (Beijing Hengjiu Scientific Instrument Factory) under a dynamic air (dried) atmosphere at a heating rate of $10^{\circ} \mathrm{C} \mathrm{min}^{-1}$ from room temperature to $700{ }^{\circ} \mathrm{C}$. The specimen size for the cone calorimetry experiments was $100 \times 100 \times 3 \mathrm{~mm}^{3}$ by PX-07-007 (Phoenix quality inspection instrument co., LTD, Shanghai, China). The char residues after the CONE test were studied with a scanning electron microscope (KYKY-EM3200, China). The samples were gold-coated before scanning to provide an electrically conductive surface. An accelerating voltage of $20 \mathrm{kV}$ was used while we recorded the scanning electron micrograms. The elemental analyses of kaolinite and KUIC were studied by an energy-dispersive X-ray spectrometer (EDS, Ns-7 Thermo Fisher Scientific, Waltham, MA, USA) equipped with a scanning electron microscope (SEM, KYKY-EM3200, Beijing, China).

\section{Conclusions}

In this study, the liquid phase interdressing method was used to insert DMSO into kaolin to obtain a K-DMSO precursor, and then replace DMSO with urea to obtain KUIC. UP/APP/KUIC composites were prepared, in which APP enhances the flame retardancy and KUIC improves the thermal properties of the UP resin. A total of $15 \mathrm{phr}$ of APP and $3 \mathrm{phr}$ of KUIC were doped into UP to obtain a 28.0\% LOI, in which KUIC has a better flame retardant efficiency than kaolinite. Compared with UP, the THR and TSP decreased reduced from $10.0 \times 10^{4} \mathrm{MJ}$ and $197.5 \mathrm{~m}^{2} \cdot \mathrm{kg}^{-1}$ for the control UPR sample to $6.6 \times 10^{4} \mathrm{MJ}$ and $121.7 \mathrm{~m}^{2} \cdot \mathrm{kg}^{-1}$ for the UP/APP/KUIC composites, respectively. The tensile strength and impact strength of UP decreased with increases in the APP loading, while it increased with the increase in kaolinite and KUIC.

The APP in UP/APP/KUIC composites began to decompose at relatively low temperatures, which could catalyze the decomposition and carbonization of UP to form carbonaceous materials, leading to a low thermal stability and $R_{\max }$ and less weight loss. Meanwhile, the KUIC in the UP/APP/KUIC composites increased the thermal stability and char yields. Ultimately, a residual char with a honeycomb-like structure is obtained with a better heat insulation and mechanical properties during the combustion of the UP/APP/KUIC composites by the presence of $12 \mathrm{phr}$ of APP and $3 \mathrm{phr}$ of KUIC, which could protect the underlying materials from further burning and pyrolysis and achieve a good flame retardancy.

Author Contributions: Conceptualization, L.Y. and X.Z. (Xuan Zhou); methodology, M.G.; software, J.L.; validation, L.Y., X.Z. (Xuan Zhou), and M.G.; formal analysis, X.Z. (Xiaoqian Zhang); investigation, Y.S. and T.Z.; resources, L.Y.; data curation, T.F. and Z.S.; writing—original draft preparation, J.L.; writing—review and editing, L.Y.; visualization, Y.L.; supervision, M.G.; project administration, X.Z. (Xuan Zhou); funding acquisition, L.Y. All the authors have read and agreed to the published version of the manuscript.

Funding: This research was funded by the Hebei Province Science Foundation for Youths (E2019508144) and the Fundamental Research Funds for the Central Universities (Nos. 3142017099, 3142017098, 3142019041).

Conflicts of Interest: The authors declare no conflict of interest. 


\section{References}

1. Barile, C.; Casavola, C.; De Cillis, F. Mechanical comparison of new composite materials for aerospace applications. Compos. Part B Eng. 2019, 162, 122-128. [CrossRef]

2. Wang, Z.Y.; Guo, H.J.; Zhou, H.; Ouyang, X.F.; Jiang, D.; Li, J.H.; Guo, Q.P.; Tang, J.; Yang, C.C. Effect of the Chain Structure of Self-Emulsifying Polyester Sizing Agent on ILSS of Carbon Fiber/Unsaturated Polyester Resin Composites. Polymers 2019, 11, 1528. [CrossRef] [PubMed]

3. Wazarkar, K.; Kathalewar, M.; Sabnis, A. Flammability Behavior of Unsaturated Polyesters Modified With Novel Phosphorous Containing Flame Retardants. Polym. Compos. 2017, 38, 1483-1491. [CrossRef]

4. Nazaré, S.; Kandola, B.K.; Horrocks, A.R. Flame-retardant unsaturated polyester resin incorporating nanoclays. Polym. Advan. Technol. 2006, 17, 294-303. [CrossRef]

5. Kandola, B.K.; Krishnan, L.; Deli, D.; Ebdon, J.R. Blends of unsaturated polyester and phenolic resins for application as fire-resistant matrices in fibre-reinforced composites. Part 2: Effects of resin structure, compatibility and composition on fire performance. Polym. Degrad. Stab. 2015, 113, 154-167. [CrossRef]

6. Reuter, J.; Greiner, L.; Schonberger, F.; Doring, M. Synergistic flame retardant interplay of phosphorus containing flame retardants with aluminum trihydrate depending on the specific surface area in unsaturated polyester resin. J. Appl. Polym. Sci. 2019, 136, 47270. [CrossRef]

7. Kuzdzal, E.; Cichy, B.; Kicko-Walczak, E.; Rymarz, G. Rheological and fire properties of a composite of unsaturated polyester resin and halogen-free flame retardants. J. Appl. Polym. Sci. 2017, 134, 44371. [CrossRef]

8. Yu, Y.; Chen, Z.Q.; Zhang, Q.W.; Jiang, M.W.; Zhong, Z.H.; Chen, T.T.; Jiang, J.C. Modified montmorillonite combined with intumescent flame retardants on the flame retardancy and thermal stability properties of unsaturated polyester resins. Polym. Adv. Technol. 2019, 30, 998-1009. [CrossRef]

9. Jiang, M.W.; Zhang, Y.S.; Yu, Y.; Zhang, Q.W.; Huang, B.J.; Chen, Z.Q.; Chen, T.T.; Jiang, J.C. Flame retardancy of unsaturated polyester composites with modified ammonium polyphosphate, montmorillonite, and zinc borate. J. Appl. Polym. Sci. 2019, 136, 47180. [CrossRef]

10. Khalili, P.; Tshai, K.Y.; Hui, D.; Kong, I. Synergistic of ammonium polyphosphate and alumina trihydrate as fire retardants for natural fiber reinforced epoxy composite. Compos. Part B Eng. 2017, 114, 101-110. [CrossRef]

11. Petsom, A.; Roengsumran, S.; Ariyaphattanakul, A.; Sangvanich, P. An oxygen index evaluation of flammability for zinc hydroxystannate and zinc stannate as synergistic flame retardants for acrylonitrile-butadiene-styrene copolymer. Polym. Degrad. Stab. 2003, 80, 17-22. [CrossRef]

12. Cid, F.; Kochifas, P.; Mansilla, H.D.; Santander, P.; Yanez, J.; Amarasiriwardena, D. New subcritical fluid nebulizer $(\mathrm{ScFN})$ for improving the determination of inorganic tin in gunshot residues by flame furnace-atomic absorption spectrometry. Microchem. J. 2016, 125, 29-33. [CrossRef]

13. Lin, Y.; Yu, B.; Jin, X.; Song, L.; Hu, Y. Study on thermal degradation and combustion behavior of flame retardant unsaturated polyester resin modified with a reactive phosphorus containing monomer. RSC Adv. 2016, 6, 49633-49642. [CrossRef]

14. Wang, D.; Kan, Y.C.; Yu, X.J.; Liu, J.J.; Song, L.; Hu, Y. In situ loading ultra-small Cu $2 \mathrm{O}$ nanoparticles on 2D hierarchical $\mathrm{TiO}_{2}$-graphene oxide dual-nanosheets: Towards reducing fire hazards of unsaturated polyester resin. J. Hazard. Mater. 2016, 320, 504-512. [CrossRef] [PubMed]

15. Zatorski, W.; Salasinska, K. Combustibility studies of unsaturated polyester resins modified by nanoparticles. Polimery 2016, 61, 815-823. [CrossRef]

16. Ran, G.; Liu, X.; Guo, J.; Sun, J.; Li, H.; Gu, X.; Zhang, S. Improving the flame retardancy and water resistance of polylactic acid by introducing polyborosiloxane microencapsulated ammonium polyphosphate. Compos. Part B Eng. 2019, 173, 106772. [CrossRef]

17. Qin, Z.; Yang, R.; Zhang, W.; Li, D.; Jiao, Q. Synergistic barrier effect of aluminum phosphate on flame retardant polypropylene based on ammonium polyphosphate/dipentaerythritol system. Mater. Des. 2019, 181, 107913. [CrossRef]

18. Tabatabai, H.; Janbaz, M.; Nabizadeh, A. Mechanical and thermo-gravimetric properties of unsaturated polyester resin blended with FGD gypsum. Constr. Build. Mater. 2018, 163, 438-445. [CrossRef] 
19. Cinausero, N.; Howell, B.; Schmaucks, G.; Marosi, G.; Brzozwski, Z.; Cuesta, J.L.; Nelson, G.; Camino, G.; Wilkie, C.; Fina, A. Fire Retardancy of Polymers: New Strategies and Mechanisms; Royal Society of Chemistry: London, UK, 2008.

20. Tang, Q.; Xie, X.L.; Li, C.J.; Zhen, B.W.; Cai, X.L.; Zhang, G.Z.; Zhou, C.H.; Wang, L.J. Medium-chain triglyceride/water Pickering emulsion stabilized by phosphatidylcholine-kaolinite for encapsulation and controlled release of curcumin. Colloids Surf. B Biointerface 2019, 183, 110414. [CrossRef]

21. Zhu, B.L.; Qi, C.L.; Zhang, Y.H.; Bisson, T.; Xu, Z.H.; Fan, Y.J.; Sun, Z.X. Synthesis, characterization and acid-base properties of kaolinite and metal (Fe, Mn, Co) doped kaolinite. Appl. Clay Sci. 2019, 179, 105138. [CrossRef]

22. Chen, J.J.; Han, J.C. Comparative performance of carbon nanotubes and nanoclays as flame retardants for epoxy composites. Results Phys. 2019, 14, 102481. [CrossRef]

23. Marliana, M.M.; Hassan, A.; Yuziah, M.Y.N.; Khalil, H.P.S.A.; Inuwa, I.M.; Syakir, M.I.; Haafiz, M.K.M. Flame Retardancy, Thermal and Mechanical Properties of Kenaf Fiber Reinforced Unsaturated Polyester/Phenolic Composite. Fibers Polym. 2016, 17, 902-909. [CrossRef]

24. Pavlidou, S.; Papaspyrides, C.D. A review on polymer-layered silicate nanocomposites. Prog. Polym. Sci. 2008, 33, 1119-1198. [CrossRef]

25. Liu, Q.F.; Zhang, S.; Cheng, H.F.; Wang, D.; Li, X.G.; Hou, X.J.; Frost, R.L. Thermal behavior of kaolinite-urea intercalation complex and molecular dynamics simulation for urea molecule orientation. J. Therm. Anal. Calorim. 2014, 117, 189-196. [CrossRef]

26. Elbokl, T.A.; Detellier, C. Kaolinite-poly (methacrylamide) intercalated nanocomposite via in situ polymerization. Can. J. Chem. 2009, 87, 272-279. [CrossRef]

27. Li, Y.; Zhang, B.; Pan, X. Preparation and characterization of PMMA-kaolinite intercalation composites. Compos. Sci. Technol. 2008, 68, 1954-1961. [CrossRef]

28. Madejova, J.; Komadel, P. Baseline studies of the clay minerals society source clays. Clay Clay Min. 2001, 49, 410-432. [CrossRef]

29. Ledoux, R.L.; White, J.L. Infrared studies of hydrogen bonding interaction between kaolinite surfaces and intercalated potassium acetate, hydrazine, formamide, and urea. J. Colloid Interface Sci. 1966, 21, 127-152. [CrossRef]

30. Hoang, D.; Nguyen, T.; An, H.; Kim, J. Organo-phosphorus flame retardants for unsaturated polyester derived from recycled poly (ethylene terephthalate). Macromol. Res. 2016, 24, 537-546. [CrossRef]

31. Jia, P.Y.; Hu, L.H.; Zhang, M.; Zhou, Y.H. TG-FTIR and TG-MS analysis applied to study the flame retardancy of PVC-castor oil-based chlorinated phosphate ester blends. J. Therm. Anal. Calorim. 2016, 124, 1331-1339. [CrossRef]

32. Gao, M.; Wu, W.; Yan, Y. Thermal degradation and flame retardancy of epoxy resins containing intumescent flame retardant. J. Therm. Anal. Calorim. 2009, 95, 605-608. [CrossRef]

33. Yang, J.X.; Kong, X.J.; Xu, D.H.; Xie, W.J.; Wang, X.L. Evolution of the polydispersity of ammonium polyphosphate in a reactive extrusion process: Polycondensation mechanism and kinetics. Chem. Eng. J. 2019, 359, 1453-1462. [CrossRef]

34. Grexa, O.; Lubke, H. Flammability parameters of wood tested on a cone calorimeter. Polym. Degrad. Stab. 2001, 74, 427-432. [CrossRef]

35. Cai, J.; Heng, H.M.; Hu, X.P.; Xu, Q.K.; Miao, F. A facile method for the preparation of novel fire-retardant layered double hydroxide and its application as nanofiller in UP. Polym. Degrad. Stab. 2016, 126, 47-57. [CrossRef]

36. Shao, Z.B.; Deng, C.; Tan, Y.; Chen, M.J.; Chen, L.; Wang, Y.Z. Flame retardation of polypropylene via a novel intumescent flame retardant: Ethylenediamine-modified ammonium polyphosphate. Polym. Degrad. Stab. 2014, 106, 88-96. [CrossRef]

37. Li, S.M.; Ren, J.; Yuan, H.; Yu, T.; Yuan, W.Z. Influence of ammonium polyphosphate on the flame retardancy and mechanical properties of ramie fiber-reinforced poly (lactic acid) biocomposites. Polym. Int. 2010, $59,242-248$. 
38. Xiao, F.P.; Guo, R.; Wang, J.G. Flame retardant and its influence on the performance of asphalt-A review. Constr. Build. Mater. 2019, 212, 841-861. [CrossRef]

39. Tsunematsu, K.; Tateyama, H. Delamination of Urea-Kaolinite Complex by Using Intercalation Procedures. Rep. Kyushu Natl. Ind. Res. Inst. 2001, 82, 1589-1591. [CrossRef]

Sample Availability: Samples of the compounds are not available from the authors.

Publisher's Note: MDPI stays neutral with regard to jurisdictional claims in published maps and institutional affiliations.

(C) 2020 by the authors. Licensee MDPI, Basel, Switzerland. This article is an open access article distributed under the terms and conditions of the Creative Commons Attribution (CC BY) license (http://creativecommons.org/licenses/by/4.0/). 